\title{
The Gaps in Legal Systems: A Deontic Assesment
}

\section{凤日adim Verenich}

PhD Student, Research Partner, Institute of Philosophy and Semiotics, Faculty of Arts and Humanities, Tarty University. Address: 2 Jakobi Str., Tartu 51014, Estonia. E-mail: vadimverenich@ gmail.com

\section{A}

From logical point of view, it is worth discussing problem of legal gaps that is very important in the analysis of legal systems. The article belows contributes to the the analisys of so-called legal gaps from the perspective of deontic logic. In the beginning of the paper, after discussing certain properties of legal systems - completeness, consistency and contingency - on the basis of analytical methodology of legal positivism based on Dworkin-Hart's debate about closure rules, in is describing different types of closure rules, which are employed for closing the legal systems. The paper compares the similarities and differences between different approaches to the studies of legal gaps. It is found that similarities between logical modalities and types of legalism makes possible to extend analysis of closure rules by introducing deontic modalities; the article explores the perspectives of such analysis. We introduce logical principles underlying two main types of legalism - Anglo-Saxon and continential ones. Drawning upon the basic principles of modal logic, we briefly sketch the prior history, development and current state of studies in the field of deontic logic. The paper suggests that it should be possible to develop a deontic assessement of the closure rules in legal systems; the first goal of the paper is achieved by spelling out differences between deontic modalities in open and closed legal systems. The final section of the paper is dedicated to analysis of deontic modalities employed for generating such closure rules.

\section{0-1目 Keywords}

legal system, deontic logic, closure rules, deontic square, normative gaps, axiological gaps.

Citation: Verenich V. (2017) The Gaps in Legal Systems: Deontic Assessment. Pravo. Zhurnal Vysshey shkoly ekonomiki, no 4, pp. 59-72 (in English)

JEL: K10

DOI: $10.17323 / 2072-8166.2017 .4 .59 .72$

\section{The Completeness of Legal System and Gaps}

Any normative system, specifically a legal one, tacitly assumes certain general closure principles that establish relations between the spheres of actions subjected to modes of normative regulation. From the perspective of legal science, every legal system of positive law is supposedly assumed to be consistent, complete, and closed under norm of closure. The principle of completeness means that the legal system already includes a legal regulation for each possible case that could occur from universe of all possible cases $^{1}$, the principle of consistency

\footnotetext{
${ }^{1}$ See: Bulygin E. Legal Dogma and the Systematization of Law // Rechtstheorie, 1986, no. 10, pp. 193-210.
} 
dictates that within the same legal system no legal case can be regulated by two inconsistent normative regulations, in other words, there is no explicit conflict between norms. Yet, as we have learned from legal practice, there have always been, are, and will be situations that have been left without legal regulation because either legislator does not foresee the existence of certain factual situation or doesn't intend to enact regulation. Even legal positivism would have to accept the incompleteness of legal systems, for example in Hans Kelsen's pure theory of law paves the way for acknowledging of gaps: the law is inconclusive as it is incomplete in those cases when there is a conflict of interests present which legal system does not prevent from occurring; no legal system has sufficient rules to prevent all possible conflicts of interest from happening, i.e. it is not possible to prevent all unforeseen incursion of unregulated conflicting interests into the domain of law ${ }^{2}$.

In fact, legal scholars have distinguished two entirely separate types of gaps in law axiological gaps and normative gaps. The idea that two different types of gaps can occur is particularly significant for analysis of incomplete systems of law. Hence to speak of the legal gap is first and foremost to focus on describing the differences between two aforementioned types of gaps.

Let us begin with the latter type of normative gaps. According to Alchourrón and Bulygin, the normative unity, or, rather, the normative completeness of legal system is vested upon a special rule of closure, which authors believe to have explicit normative properties - the rule of normative closure, grounded on what is known as 'deontic logic's. Having made this claim, Alchourrón and Bulygin demonstrated that the normative closure of legal system would deliberately require the to accept ascription of deontic properties to certain action - if no deontic property can be ascribed to a certain action, a deontic property make ascribed to that action, to avoid the gap, i.e uncertainty of action and its consequences in legal domain ${ }^{4}$.

Since every legally relevant action is accompanied by a deontic properties (dispositions), ascribed to action, the law is always applicable, as Kelsen said: "a so-called gap in the law is not a legal gap, but a situation in which the application of the law as it is to the particular case is so absurd and unjust that the judge assumes that the law is not to be applied to the case" ${ }^{\text {. }}$

Seen from this perspective, legislating, is just a special case of formulating deontic properties of action by authorative groups. This type of closure rule is best exemplified in what legal scholars call 'legalism'. There is a division between two dominant types of legalism, each type of legalism has its intrinsic value for shaping the entire legal system.

\section{Two Types of Legalism}

The legalism of first type (1) is principle of prohibition: if something is not explicitly prohibited in legal system, then it is permitted. Some authors believe that the "sealing" principle mentioned before, is more compatible with Common Law-like jurisdictions, privileging permissions over sanctioned obligations as something primary. The principle posits that the judge is not allowed to extend deliberately the whole of legal prohibition to all unregulated acts. As it is evident from civil cases, an absence of categorical orders to participants of legal relations to act in a certain manner is also typical for the dispositive method of civil regulation in many

\footnotetext{
2 Kelsen H. Pure Theory of Law. Berkeley, 1967. P. 243.

${ }^{3}$ Alchourrón C., Bulygin E. Normative Systems. New York-Wien, 1971.

${ }^{4}$ Ibid. Chapter 6. Sec. 2.

${ }^{5}$ Kelsen H. Op. cit. P. 242.
} 
legal systems. Using this closure principle, it is fair easy to demonstrate that legal systems can be distinguished as closed or open according as they do or do not endorse the maxim, what is not forbidden is permitted. In their famous paper, Alchourrón and Bulygin have advanced von Wright's idea ${ }^{6}$ that there are many kinds of permission, of which authors pay special attention to distinction between $a$ weak and a strong permission ${ }^{7}$. In case of a strong permission, an act is said to be permitted when it is not forbidden, the authority considered its normative status and decided to permit it by promulgating a permissive norm. A weak permission is always extra-normative: "an act is said to be permitted in weak sense if it is not forbidden and a norm regulating of this act is not enacted". The same "weak/strong" distinction has been extended to classification of prohibitions ${ }^{9}$. Strong prohibition is a positive norm enacted to the effect when something is forbidden, while weak prohibition is the absence of a positive norm to the effect that something is allowed.

This conclusion raises question. It should already be apparent from the previous discussion that the completeness of legal systems in first type of legalism ("principle of permission") is ensured by the strong-permitted version of prohibition principle, but does this principle provide a support for the contingency of legal systems? It is assumed that the contingency of legal system is said to be a means of sustaining its autonomy. Kelsen conceived of strong prohibition as of a positive norm, and if this is so, then the question - whether or not principle of strong prohibition exists in legal systems - is to be answered in contingent manner, since, contrary to Kelsen's assumptions, the principle of prohibition does not have the universal property of belonging to all legal systems, they can be closed or open according to whether or not they contain, as their constituent part, a strong principle of prohibition, which is strong enough to close normative systems ${ }^{10}$. Envisaged from a perspective of contingency, a strong principle of prohibition is far from being a necessary element of all legal systems, with exception of strong principles in criminal law, such as nulla poena sine lege. At the same time, the imminent coexistence of conflicting interests in the legal domain brings about the presence of weak prohibitions, which are compatible with all legal systems having gaps - the weak principle of obligation is a proposition which is, unlike strong prohibition, is always necessarily true (indeed, it is always tautologically true that all acts that are nor prohibited in a legal system are nor prohibited in it). It thus follows that the strong principle of prohibition ideed provides support to the contingency of legal system, while the weak principle of prohibition does not.

Let's turn to legalism of second type (2), which is manifested in "the principle of obligation" if something is not permitted, then it is prohibited - is often said to be an important feature of European continental legal systems, which are oriented towards German legal systems. To promote clarity in ambiguous matter of obligation, we should once again to distinguish between a strong principle of obligation and a weak principle of obligation version. A strong obligation is a positive norm to the effect that something is required, while weak obligation is the absence of a positive norm to the effect that something is gratuitous (i.e., permitted not to obtain).

${ }^{6}$ Described in: Kelsen H. Die Grundlagen der Naturrechtslehre. Österreichische Zeitung für öffentlisches Recht. 1963, no. 13, pp. 1-37.

7 Alchourrón C., Bulygin, E. Pragmatic Foundations for a Logic of Norms. Rechtstheorie. 1984, no. 15, pp. 453-464.

${ }^{8}$ Alchourrón C., Bulygin E. Normative Systems. P. 125.

9 Bulygin E. Kelsen on the Completeness and Consistency of Law / D'Almeida L. et al. (eds.) Kelsen Revisited. New Essays on the Pure Theory of Law. Oxford, 2013. P. 225-243.

10 Ibid. P. 235, 240. 
According to Jan Woleński ${ }^{11}$, the logical analysis of deontic relations between the domain of normative requirements (including permissions and obligations) and its complement in universum of possible human actions, - the domain of indifferences - proves that even if closure rules of both type of legalism (1) and (2) can be formalised into same tautologies of deontic logic, the closure principles are not equivalent by content ${ }^{12}$. From the logical perspective, the closure rule in legalism (2) is equivalent to the tautology "no action can be prohibited and permitted at the same time in any given legal system"13. Indeed, the converse restatement of legalism (2) would yield to an undesirable proposition - if it is not strongly permitted than it is forbidden - which is not acceptable for strong permission, since it would collapse strong principle of permission into a plain permission.

Legalism of first type (1) closes normative system in a rational way, while the closure principle in second type of legalism (2) is questioned by the fact that legal systems are always incomplete. As a matter of fact, for many reasons legal systems do not attempt to create a complete list of all non-permitted (prohibited) actions, intentionally leaving spaces in regulation to be filled later by adding new norms, formed on the basis of juridical precedents, customs, etc. The attempt to codify all possible prohibited actions has always proved to be difficult. It is very common practice in law to permit acting in certain way under certain circumstances, while otherwise the same acting is prohibited. Some acts are allowed by norm or legal authority as 'legally indifferent' (de jure freedom), while other acts are 'legally irrelevant' when the norm-imposed obligations are not enforced and in absence of any constraints, an individual have a de facto freedom to do whatever he or she wants to.

Thus, it becomes obvious that legal systems may be classified as either closed or open according to the type of closure they operate on, i.e. as to whether they do or do not follow the maxim, what is not prohibited is permitted ${ }^{14}$. Therefore, such distinguishing attributes of legal system as it is its openness, must be considered in "the process of logical analysis, which would make necessary introducing new modalities for open and closed legal systems"15.

Axiological gap occurs in legal system with respect to legal reasoning in challenging cases - a value judgement about axiological relevance of norms from the internal point of view - for example, when moral exceptions to existing norms has been omitted, when legal system ought to contain them from moral point of view. In the case of an axiological gap, interpreter - a judge - is required to eliminate apparent conflict between the proposed and the existing solution (which is unsatisfactory due to axiological considerations), remaining at the same time as close as it is possible to what has been deemed relevant by original legislator or legal authority, which passed a norm that regulates a case in question. This perplexing task is left to the discretion of judges, who have authority to make legally bound decision according to their discretion.

The topic of judicial discretion became an important topic in Dworkin-Hart debate on whether there could exist gaps in the legal system. In developing his theory of a legal system, Hart appears to reject formalist approach, following a positivist tradition and in doing so he

${ }_{11}$ Wolenski J. Three Contributions to Legal Philosophy / Jadacki J. and Paśniczek J. (eds) The Lvov-Warsaw School: The Next Generation. Amsterdam — New York, 2006. P.195-213.

12 Ibid. P. 198.

${ }^{13}$ Czelakowski J. Action and Deontology / Ejerhed E., Lindström S. (eds.) Logic, Action and Cognition. Dordrecht, 1997. P. 47-88.

14 Stone J. Non Liquet and the Function of Law in the International Community / British Year Book of International Law. 1959, vol. 35, pp.124-161.

15 Mullock P. The Stone-Tammelo Deontic Logic // Logique et Analyse. 1975, no. 18, pp. 65-89. 
accepts that laws consist in rules created by legislator, as well as the concept of incomplete legal systems - when there is a case that does not fall under an existing rule, there is a normative gap $^{16}$. However, unlike Kelsen, he also seems to agree that judges have a significant discretion, because rule of recognition would require them to decide cases even in situation of legal gaps. Attacking the main thesis of positivism that legal gaps are to be filled by discretionary decisions, Dworkin rejects not only the discretion, but also the very idea that the legal system could be incomplete and containing gaps, because when a case is brought to court, the judge must decide to protect basic rights of the parties, based upon the judge's weighing of the rights of the parties. When a rule is absent, then, according to Dworkin, the judge must weigh principles, because even in case of absence of rules, law is not uncompleted, but always augmented by legal principles ${ }^{17}$. Dworkin maintains since the legal system must be always complete and consistent, there is always one right answer to legal problem, a closure rule reflecting the pre-existing rights of the parties (the rights themselves are constructed from the 'constitutional' principles). According to Dworkin, a closure rule comes into full operational force with a compelling argument 'one right answer' thesis, which is meant to close all gaps ${ }^{18}$.

Dworkin argues in support of his 'right-answer thesis' against the existence of 'logical spaces' in the legal system: there is no logical space between the propositions 'this is a valid contract' and 'this contract is invalid', because there is no any third option between rules ${ }^{19}$. However, it is implied that logical spaces could exist between legal rules and moral principles. What is interesting is that following the law of excluded middle and the logic of dispositive concepts, Dworkin mistakenly makes assumption that positivists recognize the existence of logical spaces both between that he called dispositive concepts (the concepts that have been stipulated by the legislator and must be either true or false and for which the absence of truth would mean the falsity) and in the absence of the of such concepts.

$$
\begin{gathered}
\text { Let } \left.p={ }_{\text {def }} \text { (contract is valid }\right) \\
\text { non- } \left.p={ }_{\text {def }} \text { (contract is not valid }\right)
\end{gathered}
$$

In Dworkin's first claim it is denied that non- $p$ is equal to $\neg p$ (that is, there is a logical space between non- $p$ and $\neg p$ ). The second claim supposes that non- $p$ and $\neg$ p could be possibly identical concepts, but in some cases, neither non- $p$ or $\neg p$ is true. However, the first claim turns out to be immaterial for legal positivism, because "positivists hold that legal propositions are true if and only if some set of facts obtains such as the sovereign having commanded that certain types of contracts are valid" 20 . This line of reasoning of legal positivism could be represented using the following logical formulas:

$$
\begin{gathered}
\text { Let } \left.S(p)={ }_{\text {def }} \text { (sovereign's command }\right) \\
S(p) \equiv p(\text { confusion of internal and external negations }) \\
\neg S(p) \equiv \neg p
\end{gathered}
$$

\footnotetext{
16 A problem is discussed in: Hart H. The Concept of Law. Oxford, 1961. P. 128.

17 Dworkin R. The Model of Rules. Taking Rights Seriously. London, 1977, pp. 14-45.

18 Jackson B. A Journey into Legal Semiotics // Actes Sémiotiques. 2017, no. 120, pp. 1-43.

19 Dworkin R. No Right Answer? / Hacker P., Raz J. (eds.) Law, Morality, and Society. Oxford, 1977, pp. 58-84.

${ }^{20}$ Alexander L., Bayles M. Hercules or Proteus? The Many Theses of Ronald Dworkin // Social Theory and Practice. 1980, no 3-4, pp. 267-303.
} 
Alexander and Bayles obtained the following the formula by expressing positivists' adherence to the sovereign's command:

$$
S(p) \square p
$$

that is to be translated in the proposition $p$ is true if and only if the sovereign $S$ has commanded. The subsequent analysis of proposition of that type would suggest the possibility of two discriminable internal and external negation. Suppose that we postulate in positivists' footsteps that if $S(p)$ is internally negated (that is, one or more components of the proposition is negated) - then $\neg p$ must follow:

$$
S(\neg p) \square \neg p
$$

From the positivist point we do not have any other option but to concede with statement that if $\neg p$ is a true (legal proposition if the sovereign has commanded $\neg p$. It is worth mentioning that the same approach would not work in case of external negation, when the proposition as a whole is being negated. It would be difficult to agree that the following formula would be true in legal positivism for the lack of the command/sanction to $\mathrm{p}$ would not imply that it is the case that $\neg p$ :

$$
\neg S(p) \square \neg p
$$

That the absence of the sovereign's command (that is, the absence of dispositive concept of p) for Dworkin does not exhaust the logical space, because there is the third possibility. But if we would have addressed the issue from the positivist position, we would have taken a logical space as granted, assuming that prior to the exercise of judicial discretion the situation is legally undetermined. Unless a particular legal system has adopted a closure rule such

$$
\neg S(p) \square \neg p
$$

"then the legal position is indeterminate, and the judge has a discretion to create a new rule. But if legal system does assume such a closure rule, then legal proposition $\neg \mathrm{p}$ is true if and only if either sovereign has not commanded p or the sovereign has commanded $\neg$ p" (see Jackson 1985:199-202) $)^{21}$ :

$$
[-S(p) v S(-p)] \equiv-p \text { (exhausts the possibilities for } \neg p)
$$

Obviously, the complex domain of legal imperatives and commands cannot be adequately modelled by classical propositional logic, since permissive and prohibitive principles extend beyond the limits of propositional logic. Thus, more appropriate logical formalisation would require the recourse to deontic logic - which is, very broadly speaking the logical analysis of the normative language, as well as study of a variety of normative concepts, such as obligation (prescription), prohibition (forbiddance), permission and commitment ${ }^{22}$.

\section{Deontic Logic}

The traditional definition for deontic logic says that it comprises deductive systems which formalize imperative utterances (commands, prescriptions and norms) or ought-sentences ${ }^{23}$.

${ }^{21}$ Jackson B. Semiotics and Legal Theory. Liverpool, 1985. P.199-202.

${ }^{22}$ Åqvist L. Deontic Logic / Gabbay D., Guenthner F. (eds.) Handbook of Philosophical Logic. Vol. 8. Dordrecht-Boston-London, 2002. P.142 -264.

${ }^{23}$ Scholars of logic distinguish deontic logic - formal theory of all ought-sentences - from the logic of norms (formal theory of norms), they maintain that the former presupposes the latter, so they use both terms 
In the case of formalizing legal norms, deontic logic became an indispensable instrument of the assessment of the validity of legal norms. For a lengthy period, the development of deontic logic has been dominated by two trends, with the first trend holding that the contents of deontic sentences are actions ${ }^{24}$, while the second trend holds that the variables of the formulae of deontic logic stand for the description of states of affairs, which logicians have presented in diverse ways. In more traditional approach, action modalities have been added by special deontic modalities by building special deontic logic of action.

Let's recall that the concept of modality is usually believed to be introduced in Aristotle's 'De Interpretatione'. In short, a modality can be defined as the expression of the attitude of the speaker towards the propositional content presented in an utterance. The simplest linguistic manifestation takes the form:

\section{It is $<$ modal force $>$ that $<$ proposition $>$}

Modal categories such as obligation, permission, and prohibition, i.e. the deontic modalities, modalities of action, are at the base of all variations of modern deontic logic, but the first investigations concerning these notions can be traced back much further in. The obvious candidate for a formalization of norms and obligations is deontic logic, Leibniz's logic of legal obligations.

Leibniz, in his manuscript Elementa iuris naturalis ${ }^{25}$ introduced the deontic categories of the obligatory (debitum), the permitted (licitum) and the prohibited (illicitum) as 'modalities of law' (iuris modalia). As has already been pointed out by Schepers ${ }^{26}$ and Kalinowski ${ }^{27}$, Leibniz saw very clearly that the logical relations between the deontic modalities obligatory, permitted and forbidden exactly corresponds relations between more general alethic modalities, such as necessary, possible and impossible, and that therefore all laws and rules of alethic modal logic may be applied to deontic logic as well. Just like 'necessary', 'contingent', 'possible' and 'impossible' are related to each other, so also are 'obligatory', 'not obligatory', 'permitted', and 'forbidden'. The true greatness of Leibniz's logic of obligations consists in its ability to demonstrate that all deontic notions can be derived from traditional alethic modalities just by adding a special 'logical' constant, which Leibniz called amorally perfect man ("vir bonus") ${ }^{28}$. Vir bonus is defined as a prudent, virtuous man, a man who is endowed with due reason, must obey to laws and always do good to all other people. Leibniz defined deontic modalities as adjunction of a alethic modalities to 'vir bonus':

Iustum (licitum) est quicquid, quod viro bono possible est the permitted is whatever possible for a virtuous person to do

Equum, debitum est quicquid, quod viro bono necessarium the obligatory is whatever is necessary for a virtuous person to do

interchangeably. It seems reasonable that the name "deontic logic" has a broader extension and refers to all deductive systems which formally characterize the ought-sentences, whereas the logic of norms can be regarded as a subtype of deontic logic. See Kalinowski J. Théorie des propositions normatives // Studia Logica. 1953, no. 1, pp. 147-182.

${ }^{24}$ Action has mainly been regarded in the early works on deontic logic as a transformation of a state of affairs, rather than in the sense of a behaviour determined by intention and information-processing.

${ }^{25}$ A manuscript dating back to 1671. Published in: Leibniz G. Elementa Juris Naturalis / Sämtliche Schriften und Briefe, 6. Reihe. Philosophische Schriften. Bd.1. Berlin, 1930. P. 431-485.

${ }^{26}$ Schepers H. Leibniz' Disputationen 'De Conditionibus': Ansätzezueiner juristischen Aussagen logik // Studia Leibnitiana Supplementa.1972, no. XV, pp. 1-17.

${ }^{27}$ Kalinowski J. Un logician déontique avant la lettre: Gottfried Wilhelm Leibniz. Archiv für Rechts- und Sozial philosophien, 1971 , no. 60, pp. 79-98.

${ }^{28}$ Leibniz G. Op. cit. P. 466. 
If we express the addition of the modal operators $\square$ and $\diamond$ to vir bonus by means of a subscript ' $v$ ', these definitions can be formalized as follows (where the letter $E$ reminding of the German notion 'erlaubt' replaces more traditional $P$ for 'permitted' to avoid confusions with the operator of possibility, and $\alpha$ stands for 'action' instead of $p$ ), then Leibniz's original definitions can be represented in the following formulas:

$$
\begin{gathered}
O(\alpha) \leftrightarrow \square \square_{v}(\alpha) \\
E(\alpha) \leftrightarrow \nabla_{v}(\alpha) \\
F(\alpha) \leftrightarrow \neg \nabla_{v}(\alpha) .
\end{gathered}
$$

Final formula says that all that is unconditionally necessary will also be necessary forvir bonus:

$$
\square(\alpha) \rightarrow \square_{\mathrm{v}}(\alpha)
$$

\section{Formalisation of deontic logic}

Following Woleński ${ }^{29}$, let's take the concept of legal requirement $(\mathbf{Q})$ as primitive of deontic modalities, and divide it into $Q$ into obligation operator $(O)$ and prohibition operator $(P H)$, such as $Q \supseteq\{O, P H\}$. The concurrent standard model of deontic logic (first drafted by von Wright $^{30}$ ) employs three modal operators ' $O$ ', ' $P$ ' and ' $F$ ' (which has the same meaning as $P H$ ), where $O \alpha$ means that it is obligatory that $\alpha$ to be performed, $P \alpha$ means that it is permitted that $\alpha$ to be performed and $F \alpha$ means that it is forbidden that $\alpha$ that to be performed. The three operators are cross-defined by letting ' $O$ ' be primitive. Other deontic operators are introduced to the systems by means of thefollowing definitions:

$$
\begin{gathered}
P \alpha={ }_{d f} \neg O \neg \alpha \text { (definition of permission) } \\
F \alpha={ }_{d f} O \neg \alpha \text { (definition of prohibition) } \\
I \alpha={ }_{d f} P \alpha \wedge P \neg \alpha \text { (definition of free choice) }
\end{gathered}
$$

If one adds to von Wright's classical system the additional axiom of contingency $O(\alpha \vee \neg \alpha)$ one obtains the equivalent of the so called 'standard deontic logic' system, which is more rigorously formalized as follows ${ }^{31}$.

$$
\begin{gathered}
O(\alpha \wedge \beta) \rightarrow(O \alpha \wedge O \beta) \text { (axiom of monotony) } \\
(O \alpha \wedge O \beta) \rightarrow O(\alpha \wedge \beta) \text { (axiom of cumulativity) } \\
O \alpha \rightarrow P \alpha(\text { deontic axiom: 'whatever is obligatory is also permitted') } \\
O(\alpha \vee \neg \alpha) \text { (axiom of contingency: 'there cannot be co-existing obligations } \\
\text { to bring about } A \text { and to bring about } \neg A \text { ') }
\end{gathered}
$$

Note, that axioms of monotony and cumulativity are equivalent to von Wright's axiom of distribution $(P \alpha \vee P \beta) \leftrightarrow P(\alpha \vee \beta)$, meaning that if a disjunction of acts is permitted, then one

29 Woleński J. Op. cit. P. 198, 199.

30 Von Wright G. Deontic Logic // Mind. 1961, no. 60, pp. 1-15.

${ }^{31}$ Hansen J. Imperatives and Deontic Logic / On the Semantic Foundations of Deontic Logic. Leipzig, 2007, p. 56. 
of the disjuncts is permitted, and vice versa, deontic operator $\mathrm{P}$ is distributive over disjunction., while deontic operator $\mathrm{O}$ is distributive over conjunction.

$$
\begin{gathered}
\text { If } \alpha \leftrightarrow \beta \text { is a theorem, then } \mathrm{O} \alpha \leftrightarrow \mathrm{O} \beta \text { is a theorem, or } \alpha \leftrightarrow \beta / \mathrm{O} \alpha \leftrightarrow \\
\mathrm{O} \beta \text { (axiom of extensionality) } \\
\mathrm{O} \alpha, \mathrm{O} \alpha \rightarrow \mathrm{O} \beta / \mathrm{O} \beta \text { (modus ponens) }
\end{gathered}
$$

Using the terminology used by Leibniz and Bentham, and considering the common terminology used in the axiomatizations of deontic logic presented above, we can see that the pragmatically grounded meaning of the term permission (Perm0) is different from the formal one (Perm), as it means liberty $F$ (Faculty) to perform action $\alpha$ :

$$
\begin{gathered}
P H \alpha \leftrightarrow O \neg \alpha \\
P \alpha \leftrightarrow \neg P H \alpha \\
O \alpha \rightarrow P \alpha \\
\alpha \equiv F \alpha \equiv P \alpha \wedge P \neg \alpha
\end{gathered}
$$

\section{Deontic square and hexagon}

Upholding that is intuitive to derive from the alethic modalities all relations defined in Aristoteles' Square of Oppositions, Leibniz demonstrated analogical links between alethic and deontic modalities ${ }^{32}$. Aristotle was concerned with propositions related in terms of quantity and/or quality. Both the quality and the quantity are capable of being negated by a contradictory, as well as opposed by a contrary. In the quantificational form - "all" $(\forall)$, "some" $(\exists)$, “none" $(\forall \neg)$ and "some not" $(\exists \neg)$, — the variables generate the following four propositions ('four corners of square'), which are examples of types to which scholastic logic applied the symbols A, E, I, O: A "all", E "none", I "some" (in the sense of at least one), O "some not" (at least one not). The analogy between the alethic and deontic categories (discussed above) makes it possible to represent the deontic modalities by using the same logical principles applied to Aristoteles' Square of Oppositions:

\begin{tabular}{|l|l|l|}
\hline Types of statements & Alethic modes & Deontic modes \\
\hline A: Universal affirmative & Necessary & Obligatory \\
\hline E: Universal negative & Impossible & Forbidden \\
\hline I: Particular affirmative & Possible & Permitted \\
\hline O: Particular negative & Possible not & Omissible \\
\hline
\end{tabular}

Given the isomorphism between types of statements in Aristoteles' logic alethic modes and deontic modes, this square can then be translated to a 'deontic square'.

In the corner of deontic square are four statements, expressed in terms of the three alethic modalities 'obligatory', 'forbidden', 'permitted', 'omissible'. Horizontally, the statements in the left and right upper corner are contraries, meaning that not one statement from the left and one from the right corners can be true together. The statements in the left and right lower

${ }^{32}$ Johns C. Leibniz and the Square: A Deontic Logic for the Vir Bonus // History and Philosophy of Logic. 2014, no 4, pp. 369-376. 
corner present sub contraries, meaning that not one statement from the left and one from the right corners can be false together. Vertically we have the sub-alternatives, meaning that any statement from the right (left) upper corner implies any statement from the right (left) lower corner. The statements that stand diagonally to each other are oppositions, meaning that each statement from one corner implies that any statement from the diagonally opposite corner is false. Thus, we can assert that omission is the negation (contradiction) of prescription, prohibition is the opposite of obligation (or its contrary).

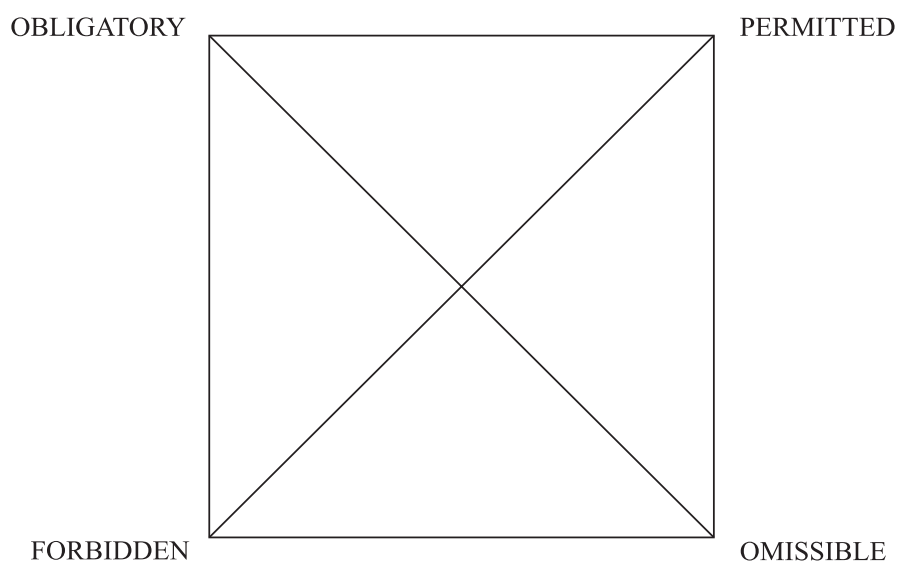

Figure 1. Deontic Square

The limits of the system of concepts represented by the deontological square are reached as soon as behaviour is concerned that philosophical tradition refers to as indifferent and normatively determined acts "supererogatory". However, the scholastics realised that the two horizontal sides of the square were not logically equivalent: I and $\mathbf{O}$ can simultaneously be true, while $\mathbf{A}$ and $\mathbf{E}$ cannot. The relationship between I and $\mathbf{O}$ came to be known as 'subcontrariety', that between $\mathbf{A}$ and $\mathbf{E}$ as 'contrariety'. In the case of subcontrariety, it is possible to affirm both I and $\mathbf{O}$ simultaneously, through a third possibility which combines them:

Some legal actions are possible (permitted) (I)

Some legal actions are not possible (omissible) (O)

Both I and $\mathbf{O}$ can be true, provided only that the 'some' in both propositions does not refer to the same type of legal actions. Blanché was one of the first scholars to observe that the usage of 'some' in many natural languages implies reference to some but not all ${ }^{33}$. Unfortunately, the relationship is not reversible. If we negate both $\mathbf{I}$ and $\mathbf{O}$ (external negations), we arrive at their contradictories: $\mathbf{A}$ and $\mathbf{E}$, which cannot stand together compatibly within a third term, but can only admit of mediation by a neutral third term (neither A nor $\mathbf{E}$ ). In the case of subalternation, we do have exclusivity in one direction: A does entail I (without any third possibility); E similarly entails O. However, I does not entail A, nor does $\mathrm{O}$ entail E. I can still be true while $\mathrm{A}$ is false; $\mathrm{O}$ can still be true while $\mathrm{E}$ is false $\mathrm{e}^{34}$. between contraries differs from that between subcontraries. This was appreciated by the scholastic commentators upon the classical square.

\footnotetext{
${ }^{33}$ Blanché R. Structures intellectuelles, essai sur l'organisation systématique des concepts. Paris, 1966.

${ }^{34}$ Jackson B. Semiotics and Legal Theory. Liverpool, 1985.
} 
Their account implies the existence of two further points, one negating both contraries, the other a point which combines both contraries. Robert Blanché sought to propose an extension to the Aristotelian square of opposition by making the relationships between contraries and contradictories more explicit. He proposed therefore a triangle of contrariety (modelled after Leibniz triangle officium, licitum and peccatum), whose corners were A, E. Moreover, he added new position $\mathrm{Y}$, associated with this new meaning. As $\mathrm{Y}$ can be obtained by the conjunction of I and $\mathrm{O}$, he eventually constructed a hexagonal shape, including an additional position $\mathrm{U}$, a 'compound' position obtained by the disjunction of $\mathrm{A}$ and $\mathrm{E}$. The position Y represents, in qualitative terms, the neutral position, which cannot be described in either positive or in negative terms. Adding two more nodes or vertices to the square-one above the top horizontal connection and one below the bottom horizontal connection of the square- yields a hexagonal shape known as the Blanchés hexagon or the Blanchés star.

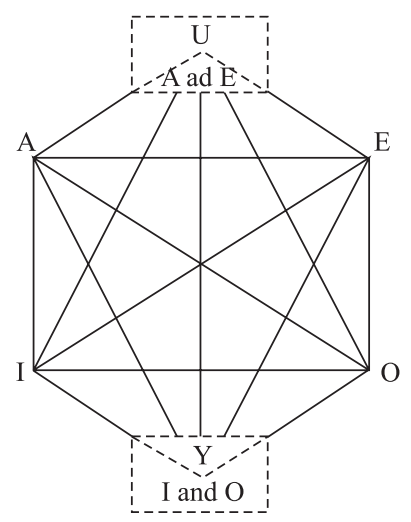

Figure 2. Deontic hexagon

The two new operators, $\mathrm{U}$ and $\mathrm{Y}$, are respectively defined in as the disjunction of the two top corners of the square and the conjunction of the two bottom corners of the square:

$$
\begin{gathered}
U \equiv A \vee E(\text { all or no }) \\
Y \equiv I \wedge O(\text { some but not all })
\end{gathered}
$$

The inclusion of two additional types of statements ( $\mathrm{Y}$ and $\mathrm{U}$ ) would generate a geometric structure known as 'logical hexagon', from which we can derive additional types. In addition to the terms already used in the square (obligatory, forbidden, permitted, and not obligatory), the hexagon also includes the terms indifferent and normatively determined. The major addition entailed by the refinement of the deontological square the deontological hexagon is the three positive deontic modalities in upper triangle - obligatory, forbidden and (normatively) indifferent - and three negative deontic modalities in lower triangle - permitted, not obligatory and normatively determined ${ }^{35}$.Using the vocabulary of deontic logic, it is possible to justify the definition of a bilaterally permission to do or not to do $-\mathrm{Y}-$ is defined by conjunction of "permitted and not obligatory". The modality of normatively determined is defined by the triadic opposition to subcontraries I and $\mathrm{O}$ and by the negation of indifferent, and, on the other hand,

${ }^{35}$ Joerden J. Deontological Square, Hexagon, and Decagon: A Deontic Framework for Supererogation // Logica Universalis. 2012, no.1/2, pp. 201-216. 
"either obligatory or forbidden". This position remains very close to the Stone's opinion, who has sought to make explicit that the modality indifferent of deontic logic is not very helpful for expressing the neutral absence ofthe dispositive concepts because it really means a permissive by a licensory norm and not obligatory ${ }^{36}$. Thus, from Stone's demonstrations, it can be seen that the minimal design of closed legal systems is closed upon the obligatory and permissive modalities (the closure rule). In open legal systems, that permit or tolerate a legal neutrality in those cases when the legal system contains no rule specifically governing a certain act or omission, a further modality of conduct, which is neither prohibited nor required. Tammelo and Klinger called the modality the allowable, which covers the permissive and the deontically neutral modalities ${ }^{37}$. It is interesting to observe from the perspective of comparative legal theory that modern Western legal systems in their classical form fall under the category of closed legal systems, where certain acts may be permitted, required or prohibited, while traditional Islamic law is more diverse and open-ended, for it leaves a space for positively allowed (recommended) or negatively disallowed (disapproved) modalities of actions. Indeed, by looking at the terminology used in Islamic law to deontologically evaluate legal acts, it is possible to distinguish five basic types (modalities):
(1) obligation (wagib, fard),
(2) prohibition (muharam),
(3) recommendation to commit an act (mandub, mustahabb),
(4) recommendation to omit an act, i.e. disapproval of an act (makruh),
(5) indifference (ibaha, mubah).

\section{Conclusion: further extensions of deontic models}

The recent studies ${ }^{38}$ have demonstrated that Leibniz's derivation of the deontic operators from alethic modal operators, is methodologically very similar to the reduction of deontic logic to alethic modal logic described by Stig Kanger ${ }^{39}$ and Alan Ross Anderson ${ }^{40}$. In their more elaborated approach, Kanger and Anderson succeeded to prove that the analogy between the alethic and deontic modal concepts (already described by Leibniz 300 years earlier) is not only useful for deriving the modalities of the former to the latter, but also very helpful for reduce deontic logic to alethic modal logic. In order to make this reduction possible Kanger added a special $Q$ constant (which is translated into natural language as 'what morality proscribes'), while Anderson achieves the same goal by incorporating another special constant $S$ ('sanction' or 'a bad state of affairs') to an arbitrary modal system. Then, a traditional deontic $O$ (it is obligatory that) operator is then defined as follows:

$$
\begin{aligned}
& \left({ }_{\text {def }} O Q\right) \mathrm{OQ}={ }_{\text {def }} \square(\mathrm{Q} \rightarrow \mathrm{\alpha}) \\
& \left({ }_{\text {def }} \mathrm{OS}\right) \mathrm{Oa}=_{\text {def }} \square(\neg a \rightarrow \alpha)
\end{aligned}
$$

36 Stone J. Op. cit.

37 Tammelo I. Outlines of Modern Legal Logic. Wiesbaden, 1969; Klinger R. Basic Deontic Structure of Legal Systems. Sydney, 1969.

${ }^{38}$ For example, see Lenzen W. Leibniz on Alethic and Deontic Modal Logic / Berlioz D., Nef F. (eds.) Leibniz et les Puissances du Language. Paris, 2005. P. 341-362.

39 Kanger S. New Foundations For Ethical Theory. Part 1. Stockholm, 1957.

${ }^{40}$ Anderson A. A Reduction of Deontic Logic to Alethic Modal Logic // Mind. 1958, vol. 67, pp. 100-103. 
In Kanger's interpretation (which is almost identical to Leibniz's interpretation), the proposition 'an action $\alpha$ is obligatory' is to be understood as 'what morality prescribes necessitates an action $\alpha$. Anderson's interpretation is rather different from that, for it privileges consequences over action, that is, the same proposition means that 'not performing an action necessitates the sanction ('leads to a bad state of affairs') ${ }^{41}$. Anderson's approach to reduction of deontic reveals its real potential as part of Meyer's reduction of deontic action logic to dynamic logic ${ }^{42}$.

Now let's discuss another problem with the first systems of deontic logic were developing as if there might be only one legislative entity, from whom the norm emanates vertically to all norm addressee ${ }^{43}$. Unfortunately, the first systems of deontic logic presented very simplistic model of normative regulation, which failed to account for reciprocal horizontal reciprocal juridical relations, such as those introduced by Hohfeld ${ }^{44}$, who built his theory of law upon the notion of a personal contract between two individuals, rather than on the notion of an impersonally permitted or a prohibited action: ' $Y$ has a duty toward $X$ that...' Moreover, a certain number of norms has a very limited and defined group of individuals, to whom these norms addresses. Hence a relation of reciprocal personal action becomes very important in any attempt ${ }^{45}$ to introduce individuals into deontic logic as variables or parameters attached to a deontic operator, by indexing deontic operators with special prefixes, meaning either the subject or the addressee of this norm. For example, in case of a norm which is recognized by all individuals locate within the same legal system (a universally valid norm), we can say that $x$ (legislative body) makes it obligatory that $\mathrm{p}$, an expression which can be also read: 'it is obligatory, with respect to the authority $x$, that $p$ ' or 'it is obligatory, toward $x$, that $p$ '.

After assigning individual prefixes to deontic operators, it is possible to introduce a new ingredient to the model, namely, personal human attitudes of deontic agents felt towards the deontic operators. One of the forerunners of modern deontic logic, Meinong conceived of strongest human feelings - desires ${ }^{46}$ - as the presentation of norms:to desire something is to be presented with it as something that ought to be. We have a modal language that gives us the means we need for a schematic description of agent-based personal deontic logic. The basic modalities constructed for such system would be

a) $O_{A N}(p)$, which is read as follows - in normative system $N$, agent $A$ is obliged to see to it that $p$;

b) $D_{N}(p)$ : the normative agent $N$ desires $p$;

c) $V_{N A}(p)$ : according to normative system $N$, $p$ counts as a violation by agent $A$;

d) $S_{N A}(p)$ : according to $N, A$ is sanctioned by the normative agent $N$ forp. ${ }^{47}$

41 Ibid.

42 Meyer J. A Different Approach to Deontic Logic: Deontic Logic Viewed as a Variant of Dynamic Logic // Notre Dame Journal of Formal Logic. 1988, no 1, pp.109-136, in which $F(\alpha)$ supposed to be read as 'action $\alpha$ is forbidden, is reduced to [a] $\mathrm{V}$, after the execution of $\alpha \mathrm{V}$ holds.

${ }^{43}$ Boella G., Van der Torre L. Obligations as Social Constructs: Advances in Artificial Intelligence: 8th Congress of the Italian Association for Artificial Intelligence. Proceedings. Lecture Notes in Computer Science. Pisa, 2003, pp. 27-38.

${ }^{44}$ Hohfeld W. Some Fundamental Legal Conceptions as Applied in Judicial Reasoning // Yale Law Journal. 1913, vol. 1, pp. 16-59.

${ }^{45}$ Kanger's theory (using the concept of action) was originally conceived as an explanation of Hohfeld's concepts, but should perhaps be rather seen as an independent theory.

${ }^{46}$ Meinong A. On Emotional Presentation. Evanston, 1972.

47 Boella G., Van der Torre L. Op. cit. P. 29. 


\section{D国 References}

Alchourrón C., Bulygin E. (1984) Pragmatic Foundations for Logic of Norms. Rechtstheorie, no.15, pp. 453-464.

Alexander L., Bayles M. (1980) Hercules or Proteus? The Many Theses of Ronald Dworkin. Social Theory and Practice, no. 3-4, pp. 267-303.

Åqvist L. (2002) Deontic Logic. In: Gabbay, D., Guenthner, F. (eds.) Handbook of Philosophical Logic, vol. 8. Dordrecht-Boston-London: Kluwer Academic Publishers, pp. 147-264.

Boella G., Van der Torre L. (2003) Obligations as Social Constructs. Advances in Artificial Intelligence. 8th Congress of Italian Association for Artificial Intelligence. Proceedings. Pisa: Einaudi, pp. 27-38.

Bulygin E. (1986) Legal Dogma and Systematization of Law. Rechtstheorie, no.10, pp. 193-210.

Bulygin E. (2013) Kelsen on the Completeness and Consistency of Law. In: D'Almeida L. et al. (eds.). Kelsen Revisited. New Essays on the Pure Theory of Law. Oxford: Clarendon Press, pp. 225-243.

Czelakowski J. (1997) Action and Deontology. In: Ejerhed E., Lindström S. (eds.). Logic, Action and Cognition. Dordrecht: Kluwer, pp. 47-88.

Dworkin R. (1977a) No Right Answer? In: Hacker P., Raz J. (eds.) Law, Morality and Society. Oxford: Clarendon Press, pp. 58-84.

Hansen J. (2007) Imperatives and Deontic Logic. On the Semantic Foundations of Deontic Logic. Leipzig: University of Leipzig Publishing, p. 56.

Hohfeld W. (1913) Some Fundamental Legal Conceptions as Applied in Judicial Reasoning. Yale Law Journal, vol. 1, pp. 16-59.

Jackson B. (1985) Semiotics and Legal Theory. Liverpool: Deborah Publications, 373 p.

Jackson B. (2017) Journey into Legal Semiotics. Actes Sémiotiques, no. 120, pp. 1-43.

Johns C. (2014) Leibniz and the Square: A Deontic Logic for the Vir Bonus. History and Philosophy of Logic, no. 4, pp. 369-376.

Joerden J.C. (2012) Deontological Square, Hexagon, and Decagon: A Deontic Framework for Supererogation. Logica Universalis, no. 1/2, pp. 201-216.

Kalinowski J. (1974) Un logician déontique avant la lettre: Gottfried Wilhelm Leibniz. Archiv für Rechts- und Sozial philosophie, no. 60, pp. 79-98.

Kelsen H. (1967) The Pure Theory of Law. Berkeley: University of California Press, $356 \mathrm{p}$.

Lenzen W. (2005) Leibniz on Alethic and Deontic Modal Logic. In: Berlioz D., Nef F. (eds.) Leibniz et les Puissances du Language, Paris: Vrin, pp. 341-362.

Meyer J. (1988) A Different Approach to Deontic Logic: Deontic Logic Viewed as a Variant of Dynamic Logic. Notre Dame Journal of Formal Logic, no. 1, pp. 109-136.

Mullock P. (1975) The Stone-Tammelo Deontic Logic. Logique et Analyse, no. 18, pp. 65-89.

Wolenski J. (2006) Three Contributions to Legal Philosophy. In: Jadacki J., Paśniczek J. (eds). The Lvov-Warsaw School: The Next Generation. Amsterdam-New York: Rodopi, pp. 195-213. 